\title{
Feasibility Analysis on the Construction of Changde Tea-culture Ecological Logistics Park in Hunan Province
}

\author{
Shijun Yuan \\ Hunan Modern Logistics College \\ Changsha, China
}

\author{
Jianhua Chen \\ Hunan Modern Logistics College \\ Changsha, China
}

\begin{abstract}
Based on the in-depth analysis of the construction background and construction necessity of Tea Culture Ecological Industrial Park project in Hunan Changde, this paper will forecast the current project construction scale and determine its main construction content.
\end{abstract}

Keywords—tea culture; logistics park; feasibility analysis

\section{INTRODUCTION}

As China's economy turns from strong to powerful, goods bearing Chinese civilization and Chinese culture will also appear, and tea has such essence and civilization. In recent years, the area of tea gardens in 18 tea-producing provinces (regions) has grown rapidly, with a total area of about 44 million mus and China's tea production exceeding 2 million tons. However, today's tea has already emerged from the category of simple crops, and has formed a huge industrial chain across the first, second and third industries and the market prospects are developing in a broader direction. The construction of the tea culture industrial park will conform to this development trend and promote the further development of China's tea industry.

\section{PROJECT CONSTRUCTION BACKGROUND}

\section{A. China Is Rich in Tea Resources, and the Demand for Tea Logistics Increases Dramatically}

China's tea production ranks first in the world. As domestic tea consumption level of China continues to increase, consumption as a whole presents a diversified, high-quality development trend. In the long run, the growth potential of China's tea industry will be huge in the future. From the domestic point of view, drinking tea has become a living habit of most Chinese people and tea has become an indispensable health-preserving drink and spiritual drink in social life. Moreover, with the popularization of people's concept of healthy consumption, tea is being accepted, loved and pursued by more and more people. From the perspective of international demand, Chinese tea exports have been maintaining a steady growth trend.
B. The Goal of "Tea Industry of 100 Billion Yuan" in Hunan Province Will Promote the Upgrade of Tea Industry in the Province

In order to further enhance the comprehensive competitiveness of tea industry in the whole province and give full play to the positive role of tea industry in modern agriculture and the construction of a strong province, the Hunan Provincial People's Government recently issued the document "Opinions on Raising the Quality and Upgrading of Tea Industry in an All-round Way", and defined the development goals and key safeguards. Hunan Province strives to build 3 million mu high-quality tea plantations by 2020 , with clonal varieties reaching more than $80 \%$ of the total area, production of 450,000 tons and annual export of more than 80,000 tons, and spares no efforts to achieve a comprehensive output value of 100 billion Yuan of tea industry, doubling the income of tea farming and tea industry in Hunan Province.

\section{Agricultural and Logistic Support Policies Guide the Direction of Eco-science and Technology Industry Logistics Park}

1) The favorable policy of logistics park promulgated by the government provides policy guarantee for project construction: As an inevitable product of the progress of modern logistics industry, the development of logistics parks is closely linked with the advancement of logistics industry by playing a great role in promoting economic development, the benefits of logistics enterprises and social benefits. In recent years, our government and enterprises have given strong support to the development of logistics parks.

In 2003, the Ministry of Land and Resources issued the "Notice on Clearing the Specific Standards and Policy Limits of Existing Development Zones". In March 2007, the State Council issued the "Several Opinions on Promoting the Accelerated Development of the Service Industry" to develop the logistics industry. In the key development areas, it is proposed to "prioritize the development of the transportation industry, improve the professionalization of logistics, social service level, and vigorously develop third-party logistics", especially as one of the key areas in the modern service industry to boost development. In March 2008, the Ministry of Commerce promulgated the Guiding Opinions on Accelerating 
the Development of Modern Logistics in the Field of Circulation. In terms of policies and measures, it clearly put forward the policy support for modern logistics enterprises and logistics parks in the field of circulation and logistics parks with strong radiation capability to upgrade and improve warehousing facilities and information systems. In March 2009, the State Council issued the "Logistics Industry Adjustment and Revitalization Plan", which put forward the guiding ideology of "establishing a modern logistics service system to promote the development of other industries by logistics services", and included the "logistics park project" as one of the nine key projects.

The report of the Nineteenth National Congress of the Communist Party of China pointed out that in the coming period, China's logistics industry will enter a new stage of development centered on the improvement of quality and efficiency. It's necessary to adhere to the principle of efficiency improvement, quality improvement and innovation drive so as to polish up the quality of logistics supply and accelerate the development of modern logistics industry.

\section{NeCESSITY OF PROJECT CONSTRUCTION}

\section{A. Project Construction Will Promote Urban Logistics Construction in Changde City}

As an important part of the national economy, the logistics industry is a composite service industry that integrates transportation, warehousing, freight forwarding and information. Involving a wide range of fields, it attracts a large number of employed people and greatly promotes production and stimulates consumption, thus playing an important role in promoting industrial restructuring, transforming economic development methods, and enhancing national economic competitiveness. In recent years, the development of modern logistics has been widely valued by governments and enterprises at all levels. An important proposition has been repeatedly emphasized, that is, the logistics industry should be actively developed. Some provinces and cities in China even put forward the slogan of developing logistics as a pillar industry. As the center of logistics area in southern Hunan and the main regional logistics center in the province, Changde still lacks a large-scale and specialized warehousing and logistics hub. The construction of this project will help to fill this gap and speed up the buildup of urban logistics in Changde.

\section{B. The Construction of the Project Will Promote the Construction of Changde City to Be a Regional Modern Commercial and Trade Logistics Center of the Surrounding Areas}

Changde is adjacent to Dongting Lake in the east, Guizhou and Chongqing in the west, Changsha in the south and Jingxiang areas in the north. In recent years, with the further transfer of industries in coastal areas to the hinterland, Changde's export-oriented economy has been continuing to develop and new industrialization has been experiencing sustained advancement. In the meantime, domestic and foreign trade has been undergoing climb. It is in this context that the tea culture ecological logistics park project came into being.
As an important logistics node connecting ChangshaZhuzhou-Xiangtan urban agglomeration and Pearl River Delta urban agglomeration, this project is a professional logistics park in Changde city and even Hunan province in the field of tea industry, as well as a commercial logistics and urban distribution logistics service center of tea products. It has a linkage effect with Changsha and Changsha-ZhuzhouXiangtan areas, which is of great significance to the development of tea industry and logistics industry as well as other industries in Changde, serving the development of regional economy meaningfully.

\section{The Project Construction Will Be Beneficial to the Realization of Logistics Scale, Chain and Standardized Operation}

Changde hopes to build itself into a central city in Northwest Hunan and an important inter-provincial economic town in Hunan and Hubei through five years' efforts. Economic development has brought about strong logistics demand, but there are still many deficiencies in logistics enterprises above the registered scale in Changde City. For example, they are all small-sized enterprises; the services provided are concentrated at a relatively low level; there is a big gap in integrated value-added services; the logistics industry in Changde urgently needs comprehensive logistics parks with full functions, comprehensive services and perfect network to carry, providing comprehensive and high-quality services for the social and economic development of Changde City. So, this project conforms to the development trend of modern logistics in Changde, and it helps to realize logistics scale, chain and standardized operation.

\section{Project Construction Will Fill the Gap of Domestic Tea Industry Logistics Park Construction and Seize the High Point of Tea Industry Logistics Park}

In the thousands of logistics parks that have been built and planned in our country, there are hardly any logistics parks of professional tea industry. Most of them only provide logistics services by delimiting certain areas in agricultural products logistics parks. At present, China's tea industry is a developing industry, and its logistics demand is becoming increasingly prominent. Therefore, the demand for tea culture ecological logistics park will become increasingly obvious responsively. The construction of this project will fill the gap of domestic logistics park of tea industry and occupy the highland of it. Through the integration of resources in the tea industry chain, it will be helpful to build a professional tea industry logistics park with national influence.

\section{ANALYSIS OF THE STATUS QUO OF LOGISTICS DEVELOPMENT IN CHANGDE CITY}

The scale of logistics infrastructure is expanding rapidly, but the planning and construction of logistics park has just begun. At present, Changde City has formed a threedimensional transportation network with railway as its skeleton, highway as its meridian, civil aviation and water transportation as its supplement. The railway operation of the whole city constitutes a relatively perfect railway transportation network with Jiaozuo-Liuzhou, Luoyang- 
Zhanjiang, Shimen-Changsha and other major national transportation lines as the framework.

The total scale of logistics is continuously expanding, but the demand of social logistics is still insufficient. Changde City's logistics activities are still dominated by enterprise logistics, and the specialized and socialized logistics demand has not yet formed a scale. The insufficient logistics demand makes the development of logistics industry lack of internal motivation, which further limits the growth of logistics industry. Influenced by the traditional planned economy system, quite a number of enterprises still retain the "big and complete" and "small and base" operation and organization mode. A series of logistics activities in the process of purchasing raw materials and selling products mainly depend on the self-service of internal organizations of enterprises, but the development of third-party logistics is pretty slow. In this way, not only the growth point of logistics industry cannot be effectively excavated, but also the overall economic efficiency is restricted.

Modern logistics enterprises begin to start, but the overall management mode, management level and technical equipment of logistics enterprises are backward. At present, some industrial and commercial enterprises in Changde have accepted the concept of logistics and have provided their own logistics services. Moreover, warehousing, transportation, freight forwarding intermodal transport have began to change to third-party logistics. But generally speaking, there are only few modern logistics enterprises in the city. Most logistics enterprises are developed on the basis of material circulation enterprises under the traditional system, and most of the newly added logistics enterprises are private groups. In addition, the scale of enterprises is generally small, and the logistics technology and equipment tend to be simple. Logistics enterprises have weak service capability as well as narrow service scope, which are characterized by that most of the service contents just stay in warehousing, transportation, carrying and unloading. Few logistics enterprises can provide comprehensive logistics services, quite different from the management field of logistics enterprises in developed international and domestic areas.

\section{Project Logistics SCALE ForecAst AND CONSTRUCTION CONTENTS}

\section{A. Forecast of Logistics Park Scale}

According to the recent document "Opinions on Promoting the Quality Improvement and Upgrading of Tea Industry in an All-round Way" issued by Hunan Provincial People's Government, it is predicted that by 2020, 3 million mu of highquality tea plantations will be built, with the area of clonal varieties reaching more than $80 \%$ and the output of 450,000 tons, and the storage service area will be forecasted: the percentage of tea products serviced by this project will be preliminarily forecasted to account for $10 \%$ of the province's market share and the average annual turnover rate are calculated twice, then the total warehouse area demand is as follows:

$$
\mathrm{W}=\mathrm{q} /(\mathrm{P} * \mathrm{~K})
$$

$$
=22500 /(1 * 0.6)=37500 \mathrm{~m}^{2}
$$

In the formula:

$\mathrm{W}$ : Warehouse area, $\mathrm{m}^{2}$;

$\mathrm{Q}$ : Inventory of goods, $\mathrm{t}$,

P: Material storage capacity per square meter of effective area. Considering the different attributes of various goods, the logistics center roughly determines its storage capacity per square meter to be $1.0 \mathrm{~T}$.

$\mathrm{K}$ : Warehouse area utilization rate. The logistics center initially determines that the utilization rate of cold storage is 0.6 .

\section{B. Contents of Construction}

According to the development plan of the logistics park, the tea culture ecological logistics park will be built into a specialized tea industry chain logistics enterprise, circulation enterprise, production enterprise and other logistics operation facilities and integrated environment. Based on Changde, it ambitiously aims to serve surrounding counties and cities, radiating the provincial and even the whole country's regional professional tea industry logistics park.

According to the development assumption and market positioning of tea culture ecological logistics park, this project will build a large-scale tea culture propaganda platform, logistics infrastructure platform, large-scale e-commerce and logistics information service platform, business and trade transaction and display platform, etc. The specific contents of the project construction include comprehensive office service area, warehousing service area, trade exhibition and trading area, e-commerce and express service area, parking service, supporting service area, etc., with a total land area of $283 \mathrm{Mu}$ and a total construction area of 92820 square meters.

1) Integrated office service area: There is a comprehensive service building and a tea R\& D as well as training building in the region, with a total floor area of 10,000 square meters. Among them, the comprehensive service building covers an area of 6000 square meters, and the tea technology research and development and training building covers an area of 4000 square meters, providing business management, logistics finance, administration, logistics settlement and other services. In addition, the logistics information platform and e-commerce service platform are also arranged in this service area.

2) Storage service area: Three types of warehousing facilities, namely general warehouse, strategic warehouse and warehouse of constant temperature and humidity, will be built in the region to provide warehousing services for goods entering the logistics center. Among them, the general warehouse construction area covers 12,500 square meters; the strategic reserve construction area covers 10,000 square meters; and the constant temperature and humidity storage area covers 15,000 square meters. In addition, the refrigeration equipment room and power distribution room and other supporting facilities will be built here. 
3) Trade show and transaction service area: The region will build service areas related to tea industry, such as propaganda, exhibition, commerce and trade. Among them, the construction area of China Tea Chan College and Cultural Museum covers an area of 10,000 square meters; China Wuling Tea Culture Grand View Garden and Experience Hall covers 10,000 square meters; Ziyi Tea Culture Exhibition Center covers 5,000 square meters; and famous tea exhibition and trading service area covers 10,000 square meters.

4) E-commerce and express service area: An e-commerce distribution center with a construction area of 3000 square meters and an express operation center of 3000 square meters will be built in this area, and a freight parking lot will be also provided here.

5) Supporting service area: In this area, shift dormitories, canteens, communication rooms, garbage disposal stations, sewage treatment stations, power transformation and distribution rooms, fire pools, fire pump rooms, public restrooms, etc. will be built here with a total construction area of 4320 square meters.

\section{CONCLUSION}

Through repeated demonstration and research, the construction project of Changde Tea Culture Ecological Logistics Park in Hunan Province is conducive to improving the service level of logistics industry and promoting regional economic development because it abides by the development trend of modern logistics and tea industry in Changde City, conforms to the overall development plan of Changde City and meets the demand of tea industry for logistics services. It is feasible in both social and economic benefits.

\section{REFERENCES}

[1] Wang Xiaoling. Modern Transformation of Chinese Traditional Culture and Practical Research on Cultural Industrial Park[D]Shanghai Jiao Tong University.(2015)

[2] Zhang Yaowu, Zhang Jingshu. Constructing the Symbol of Tea Culture Creating a Famous Tea Culture City [J] Chaye Journal of Tea. 2016(03)

[3] Li Shuxue. Research on the Status Quo and Countermeasures of Tea Industry Development in Jiangxi Province [J] Agricultural Archaeology.2013 (05) 